\title{
DESIGUALDADE E DESENVOLVIMENTO NA AMÉRICA LATINA
}

\author{
Conceitos e realidades ¿opostas ou complementares?
}

\author{
Inequality and development in Latin America \\ Concepts and realities - opposed or complementary?
}

\section{DESIGUALDAD Y DESARROLLO EN AMERICA LATINA}

Conceptos y realidades ¿opuestas o complementarias? ${ }^{1}$

\author{
Mabel Manzanal ${ }^{2}$ \\ Consejo Nacional de Investigaciones Científicas y Tecnológicas -Conicet- \\ Instituto de Geografía, Facultad de Filosofía y Letras, Universidad de Buenos Aires -UBA- \\ mabelmanzanal@pert.org.ar
}

Resumo

Este artigo questiona a reconhecida e difundida diferença entre o desenvolvimento e o crescimento. Consideramos que esta não é uma antinomia significativa, está vinculada à colonialidade do poder e age restringindo o pensamento independente sobre estas questões.Postulamos que, no longo prazo, o desenvolvimento (conceito-termo usado para se referir tanto a uma proposta ou realidade) não ajuda a reduzir a polarização e desigualdade, mas, ao contrário, de gera-la. Naturalmente, este resultado é desenvolvido segundo práticas veladas que escondem as ações do poder hegemônico, entretanto e simultaneamente seestabelecempropostas idealistas de gestão.Esta análise é feita a partir de uma perspectiva crítica e empírica, usa documentação e informações sobre o crescimento e a desigualdade na América Latina e abrange a década perdida (19801990) e o período de tempo entre a crise e orecente boom de produtividade (19902012).Esta discussão visa contribuir com a difícil tarefa de desmistificar a cultura instalada e estruturada em torno do desenvolvimento.

Palavras-chave: desenvolvimento, desigualdade. América Latina, território, poder

\section{Resumen}

En este trabajo se cuestiona la reconocida y difundida diferencia entre desarrollo $y$ crecimiento. Partimos que se trata de una antinomia no significativa y ligada a la colonialidad del poder y que actúa restringiendo el pensamiento autónomo sobre estas cuestiones. Planteamos que en ellargo plazo, el desarrollo(concepto-término utilizado para referirse sea a una propuesta o una realidad) no actúa desalentando la polarización y desigualdad -aunque así se lo explicite- sino que por el contrario contribuye a generarla. Desde luego que este resultado se va desenvolviendo bajo prácticas veladas que ocultan el accionar del poder hegemónico mientras se enuncian, simultáneamente, idealistas propuestas de gestión pública. Este análisis, que se realiza desde una perspectiva crítica y empírica, utiliza documentación e información sobre crecimiento y desigualdad de América Latina, abarcando en particular los años de la década pérdida (1980-1990) y la etapa que transcurre entre la crisis y el más reciente boom productivo (1990-2012).La presente discusión buscacontribuir con un mínimo aporte a la titánica tarea de desmitificar la instalada y estructurada culturaen torno al desarrollo.

Palabras clave: desarrollo, desigualdad, América Latina, territorio, poder

Geo UERJ - Ano 14, no. 23, v. 2, $2^{\circ}$ semestre de 2012 p. 717-745

ISSN: 1415-7543 E-ISSN: 1981-9021

http://www.e-publicacoes.uerj.br/index.php/geouerj 


\section{Introducción}

Nuestro interés en este trabajo es contraponer la desigualdad social persistente que domina el panorama de América Latina -AL- al desarrollo como propuesta política, planteada en repetidas oportunidades a lo largo de la historia latinoamericana, bajo diferentes ropajes.

El desarrollo como propuesta de política refiere a la oferta de formas de acción alternativas respecto a las que se fueron formulando y llevando a cabo hasta entonces. Siempre se fijan metas de mayorbienestar social, igualdad, inclusión, distribución de ingresos, etc. Pero cuando las mismas, años después, no se alcanzan, se lo explica y justifica a partir de las malas praxis de los gobiernos de turno o de los actores locales.

En realidad, no es una situación novedosa en el devenir latinoamericano post-colonial. Una sucesión de hechos demuestran que las alternativas y posibilidades que se visualizan a través de los discursospolíticos dominantes en cada etapa histórica no condicen con lo sucedido posteriormente.

Al respecto, Esteva (1996, p. 53 y ss.) observa que la "era del desarrollo" y la identificación ampliada del subdesarrollo se gestó el 20 de enero de 1949, cuando asumió Harry S. Truman la presidencia de EEUU (1945-1953) y explícitamente dijo en su discurso inaugural: "Debemos emprender un nuevo programa audaz que permita que los beneficios de nuestros avances científicos y nuestro progreso industrial sirvan para la mejoría y el crecimiento de las áreas subdesarrolladas”. Poco más adelante, este mismo autor afirma: "Al usar por primera vez en ese contexto la palabra 'subdesarrollo', Truman cambio el significado de desarrollo y creó el emblema, un eufemismo, empleado desde entonces para aludir de manera discreta o descuidada a la era de la hegemonía norteamericana". Y, finalmente, resume: "desde entonces, el desarrollo connota por lo menos una cosa: escapar de una condición indigna llamada subdesarrollo" (cursivas nuestras).

Observamos, sin embargo y por el contrario, que cada contexto político y socioeconómico continuó manteniendo y aún acrecentando su perfil desigual en perjuicio de un sector socialmayoritario, postergado y marginal.

En particular, vale reflexionar respecto a los cambios operados durante los últimos setenta años que transcurren desde la segunda posguerra a la actualidad. Porque fue 
precisamente en los primeros años de ese período de posguerra cuando comenzaron a diseñarse y difundirse políticas de intervención pública como opción necesaria para que el mundo subdesarrollado superara su condición marginal y se asemejara en su estructura a los países desarrollados e identificados, más tarde, como "primer mundo". Durante ese período, podemos distinguir las siguientes propuestas:

\begin{abstract}
una asociada al período desarrollista de la "planificación nacional y regional" (1950-1975) y otra basada en una renovada "ortodoxia" neoliberal, con acento en el desarrollo endógeno que se ha difundido como Desarrollo Local (DL), Desarrollo Territorial (DT), Desarrollo Territorial Rural (DTR) y cuyos inicios ubicamos avanzados los primeros años de la década de los noventa (continuando hasta el presente). Este segundo período comienza luego de un interregno (1975-1995) de ruptura con el modelo desarrollista y keynesiano, intervalo temporal durante el cual se introdujo, consolidó y estabilizó el neoliberalismo (MANZANAL, 2010, p. 18).
\end{abstract}

Sin embargo, vale subrayar que han pasado setenta años de aquellos primeros intentos y no hubo desarrollo que lograra modificar la situación de desigualdad presente en AL. Son los propios organismos internacionales, que en cada momento promocionaron aquellas acciones, quienes lo reconocen (Banco Mundial -BM, Banco Interamericano de Desarrollo -BID, Organización de las Naciones Unidas para la Agricultura y la Alimentación -FAO, Comisión Económica para AL-CEPAL).

Corresponde mencionar la ausencia en estas propuestas de una preocupación de raíz auténticamente latinoamericana. Las soluciones para los problemas latinoamericanos (incluido el diagnóstico, la sistematización de antecedentes, referencias, formatos y diseños) han tenido como principal referente al pensamiento "euro centrado". Lo cual es una de las tantas cuestiones que da cuenta de la colonialidad del poder, como se irá viendo en lo que sigue.

En un trabajo anterior (MANZANAL, 2010: 28-29), y a partir de Quijano (2000, p. 82) yEscobar (2005, p. 20-21), subrayamos el rol dominante y euro céntrico que ha tenido y tiene la discusión y acción en torno al desarrollo. Por ello, coincidimos con estos autores en la necesidad de producir una "descolonización epistemológica”, como única forma de avanzar en el debate sobre el rol de los Estados-nación y consecuentemente sobre el destino de AL.Quijano (2000, p. 84-85) afirma: "el desarrollo de Estadosnación en estos países sólo ha sido viable de modo parcial y precario. Si hay algo de incompleta biografía en estas tierras es, justamente, el Estado-nación. Y mientras la colonialidad no sea erradicada, ese proceso no podrá culminar". En este contexto interpretativo se enmarca el presente análisis.

Geo UERJ - Ano 14, no. 23, v. 2, $2^{\circ}$ semestre de 2012 p. 717-745

ISSN: 1415-7543 E-ISSN: 1981-9021

http://www.e-publicacoes.uerj.br/index.php/geouerj 
Nos interesa comenzar planteando que desconocemos la mentada diferencia entre desarrollo y crecimiento $^{3}$. Consideramos que se trata de una antinomia no significativa y también ligada a la colonialidad del poder. Y, por ello mismo, restrictiva para descubrir nuevos desafíos en el pensamiento y en la discusión de estas cuestiones. Tampoco vamos a exponer y contrastar las múltiples connotaciones del desarrollo, para las que hay excelentes análisis y sistematizaciones realizadas (CASTORIADIS, C., 1980; ESCOBAR, A., 2005; ESTEVA, 1996; QUIJANO, A., 2000; SACHS, edit., 1996; entre otros).

En definitiva, desde una perspectiva crítica y empírica de largo plazobuscamosplantearque lo que se denomina desarrollo(sea desde su acepción asociada a una política o visto como resultado de una política) es en realidad un diseño, una propuesta o un hecho que no desalienta la polarización y desigualdad -aunque así se lo explicite- sino que, por el contrario, contribuye a generarla. Desde luego que se desenvuelve bajo prácticas veladas que ocultan el accionar del poder mientras se enuncian idealistas propuestas de gestión pública.

La discusión que se expone a continuación y el análisis empírico que sigue es tan sólo un mínimo aporte en la tarea de desmantelamientode esta estructura mental en torno al desarrollo que, instalada por siglos, "impregna no sólo las declaraciones oficiales sino hasta el lenguaje de los movimientos de base" (SACHS, 1996, p.5).

\section{Rasgos contradictorios que enfrentan al desarrollo y a la equidad social}

Partiendo de este encuadre analítico, consideramos que eldesarrolloes "una percepción que moldea la realidad, un mito que conforta a las sociedades" (SACHS, 1996, p. 5). Y, como tal, su dilucidación es un desafío muy difícil, pero necesario y posible. Así, por ejemplo, lo sostiene CASTORIADIS(1980, p. 209) cuando afirma que "lo único que está a nuestro alcance es destruir los mitos que, más que el dinero y las armas, constituyen el obstáculo más formidable para la reconstrucción de la sociedad humana". En principio, y como señalamos en el apartado anterior, el discurso dominante sobre desarrollo no se corresponde con la realidad, ni con los procesos sociales concomitantes de nuestras naciones latinoamericanas, especialmente cuando se observan desde una perspectiva de mediano y/o largo plazo. No es muy difícil corroborar esta afirmación. Basta, por ejemplo, con observar el mantenimiento de la desigualdad social a lo largo de décadas mientras las economías nacionales crecen, la dinámica económica de las 
grandes empresas se expande y su acumulación se acrecienta. Una mayor concentración y extranjerización de las economías nacionales se desenvuelve paralelamente con una mayor inequidad social.

En un trabajo anterior (MANZANAL, 2010,p. 19), refiriéndonos al caso de Argentina,visualizábamos la desigualdad ligada con el devenir histórico del proceso de acumulación capitalista nacional:

Cuando revisamos la historia de nuestro país, repetidamente reaparecen políticas y acciones que son, fundamentalmente, formas institucionales garantes de la reproducción social y de la acumulación del capital en sus múltiples expresiones. En definitiva, se constituyen en mecanismos de conservación, instauración y restauración de la dominación y del poder hegemónico. La creciente concentración económica y la desigualdad social que han caracterizado a la sociedad argentina en prácticamente todo su devenir histórico no pueden explicarse de otro modo. (...) Ambas ya están presentes desde el mismo período de la Organización Nacional (1860-1880) (cursiva nuestra).

Jorge Gelman(2011, p. 11)se remonta aún más atrás. En El mapa de la desigualdad en la Argentina del siglo XIXsostiene:

Ya resulta un lugar común en la literatura académica y aún en los medios de comunicación, la idea de que AL es la región del mundo más desigual del planeta. No la más pobre, pero si aquella en la que los desequilibrios entre las personas, los grupos sociales y las regiones son más profundos. (...)

Sin embargo, (...) no abundan los estudios de larga duración sobre desigualdad para el conjunto del subcontinente, ni para cada uno de sus países o regiones en particular.

En este sentido, el siglo XIX parece un laboratorio importante para abordar estas cuestiones, producto de los cambios profundos que caracterizan a la región luego de la crisis del orden colonial y que (...) parecen tener que ver con el desarrollo de importantes desequilibrios en distintos niveles

En la actualidad, la preocupación por la desigualdad a nivel mundial convoca el interés de los organismos internacionales. En 2000, la CEPAL encarga y publica un análisis de Samuel Morley sobre la desigualdad en la distribución del ingreso en AL. ${ }^{4}$ En este documento se sostiene que el alto nivel de desigualdad latinoamericano se vincula con rasgos de inequidad mayores a cualquier otra parte del mundo. Y específicamente se subraya el desigual acceso a la educación, la brecha salarial entre mano de obra calificada y no-calificada y la muy sesgada distribución de la tierra. Por todo lo cual los ricos de AL son mucho más ricos en relación al resto de la población de lo que lo son en otras partes del mundo. ${ }^{5}$ 
Actualmente, la CEPAL (2010) elaboró una propuesta alternativa titulada: La hora de la igualdad. Brechas por cerrar, caminos por abrir. Allí sostiene:

\begin{abstract}
¿Por qué hacemos nuestro el valor de la igualdad? Porque creemos interpretar un reclamo histórico largamente sostenido y postergado en las sociedades latinoamericanas y caribeñas. A partir de este reclamo se han ensayado, con mayor o menor fortuna, revoluciones y reformas, modelos de gobierno y de política, movimientos populares, acuerdos entre grupos y demandas de los más diversos actores. Pero al mismo tiempo que la igualdad respira, como valor positivo, en la memoria histórica de la región, se ha visto sistemáticamente negada por esa misma historia. En efecto, la desigualdad recorre cinco siglos de discriminación racial, étnica y de género, con ciudadanos de primera y segunda categoría. Recorre una modernización hecha sobre la base de la peor distribución del ingreso del mundo. Recorre décadas recientes en que se ha exacerbado la heterogeneidad de las oportunidades productivas de la sociedad, se ha deteriorado el mundo del trabajo y se ha segmentado el acceso a la protección social, multiplicándose las brechas por doquier. Recorre las asimetrías frente a la globalización.

Y sin embargo, cuanto más nos recorre la desigualdad, más intenso es el anhelo de igualdad, sobre todo cuando la historia se quiebra en su continuidad, el mundo entra en crisis y el futuro reclama un punto de inflexión. De este modo, la crisis iniciada en 2008 a escala global es un momento en que la igualdad aparece nuevamente como valor intrínseco del desarrollo que buscamos. Al confrontar las brechas, la sociedad migra de lo individual a lo colectivo y busca suturar las heridas de la desigualdad hilvanando el hilo de la cohesión social.

El escándalo de las desigualdades, que se exacerbaron como nunca antes en el modelo financierista que se impuso en el mundo en las últimas décadas, suscita la indignación compartida a la luz del desfondamiento de ese modelo tras la crisis. Podrán paliarse sus consecuencias financieras, pero no podrá borrarse la conciencia planetaria adquirida en este último año respecto de la arbitrariedad del modelo, ni podrá evanescerse la indignación que causan sus inequidades (cursiva nuestra).
\end{abstract}

Evidentemente, estos párrafos tienen una notable riqueza analítica.

En primer lugar, porque aceptan que esta desigualdad, la mayor del planeta, se extiende y prolonga por cinco siglos! Esto es clave, porque el largo período transcurrido da cuenta que el modelo capitalista no aporta soluciones a este problema y, por el contrario, las agrava.

En segundo lugar, porque habilitan preguntarse: ¿Qué rol cumplió la CEPAL y otros organismos internacionales en este proceso de deterioro social? ¿O acaso no participaron desde 1950-1960 en las propuestas dirigidas a superar el "subdesarrollo" latinoamericano con planes, programas y políticas de su propio diseño? ¿De qué vale el mejor diagnóstico si no se descubren y asumen las responsabilidades consecuentes?

En tercer lugar, porque se admite que bajo el modelo neoliberal (eufemísticamente llamado "financierista") las desigualdades se incrementaron como nunca antes. Aceptado esto, nos preguntamos, nuevamente, por las responsabilidades subyacentes y 
los responsables de dicha política a nivel internacional y nacional. Liberarnos, independizarnos, nos obliga a no aceptar generalidades, ni posiciones supuestamente asépticas. Sino, por el contrario, a exigir identificaciones particularizadas de los principales actores involucrados (empresas, bancos, políticos, juristas, organizaciones e instituciones) e identificar los mecanismos con los que operaron para consolidar su proceso de acumulación "financierista". Información que, seguramente, está al alcance y puede ser reconstruida por los organismos internacionales que se ocupan, como en este caso, de pensar y proponer políticas alternativas para paliar inequidades en los países latinoamericanos.

No es posible pretender avanzar a favor de la igualdad cuando no se conocen (o explicitan y analizan) adecuadamente las razones, los responsables y los mecanismos que llevan a la desigualdad cuya existencia se reconoce. Obviar esta identificación es: (i) proteger a los que se beneficiaron con la "exacerbación" de las desigualdades; (ii) utilizar la retórica para ocultar el accionar del poder que mantuvo y amplió los problemas socioeconómicos (hambre, pobreza, marginación, desocupación, precariedad) que aquejan a la mayoría de la población latinoamericana; (iii) estar de su lado, sostener sus intereses y su misma ideología. No existe, no es posible, un contexto de "objetividad" frente a los problemas latinoamericanos. En este encuadre no es creíble la pretensión de mayor igualdad y cualquier nueva alternativa será tan idealista como las anteriores para alimentar, por un tiempo, el mito de que "otro desarrollo es posible".

Efectivamente, los responsables de las políticas (entre ellos, los organismos internacionales) necesitan plantear renovadas propuestas dirigidas a alimentar, para muchos, una nueva ilusión. Lo cual se expresa cuando sostienen la necesidad de tomar en cuenta la opinión de los diferentes grupos afectados, rebelados y movilizados ante las sucesivas crisis que se vienen dando. ${ }^{6}$ Esto sucede porque se desencadena una nueva realidad. Un punto de inflexión determinado por la reacción masiva de la población, cuando toma conciencia de que ha sido engañada nuevamente. Un "ahora" que indica el momento desde el cual sí importa pensar y ocuparse de la dupla igualdad-desigualdad.

Precisamente, en el mismo documento (CEPAL,2011, p.185) aparece el reconocimiento y la preocupación por la conformación de una conciencia planetaria adquirida. Allí se reconoce que esta no se podrá modificar fácilmente porque "Las luchas sociales ampliaron los derechos y los siguen ampliando hacia sectorestradicionalmente 
excluidos".Efectivamente, esto es así y esta conciencia planetaria (por más que se la busque manipular, absorber y mantener dentro de los límites del capitalismo) es una realidad en expansión que potencia la posibilidad futura de construcción de otro modelo.Sin embargo, desde una crítica radical debemos estar atentos al hecho que estos movimientos más o menos espontáneos, más o menos organizados, pueden diluirse si no se constituyen en una resistencia social sostenida a partir de la comprensión cabal y crítica de los diversos mecanismos que el mercado y el Estado imponen para la consecución del modelo hegemónico bajo diferentes facetas. Indagar y descubrir estos mecanismos es una de nuestras tareas como investigadores de la problemática social.

Bajo esta misma preocupación sociopolítica, pero desde otro lugar y con una perspectiva más pragmática y comprometida políticamente, el ex presidente chileno Ricardo Lagos se refirióal problema de la desigualdad social de AL:

\begin{abstract}
(...) Seguimos siendo el continente más injusto cuando vemos lo que sucede con el ingreso (...) América Latina tiene un índice de desigualdad superior al 0.5 en términos de coeficiente de Gini, hoy mundialmente aceptado, donde 1 es la desigualdad absoluta y 0 es la igualdad total(...) Esta desigualdad es consecuencia de la aplicación de ciertas políticas... La distribución del ingreso de los países desarrollados agrupados en la OCDE es aproximadamente (...) después de impuestos y del gasto de los estados [de] 0.32 (...) En América Latina, en cambio, después de impuestos y considerando el gasto fiscal sólo se reduce a 0,51. Esa es la tremenda diferencia entre América Latina y los países ricos. Esa es la tarea pendiente. (...)Por ello UNASUR, recientemente, en su reunión en Lima, señaló que disminuir la desigualdad es nuestra agenda prioritaria (...)Y luego las presidentes DilmaRousseff y Cristina Fernández (...) dieron un sentido pragmático a esta política esencial: la inclusión social es fundamental $(. . .)^{7}$
\end{abstract}

Evidentemente, Lagos está aquí adentrándose en el rol de Estado frente a la desigualdad social existente en AL, vinculando estos desequilibrios con un modelo que los genera,asociado a unsupuesto "progreso y crecimiento". Precisamente, en el mismo artículo, Lagosinsiste con que"La desigualdad, cabe reiterarlo, deriva de decisiones políticas". Es decir, está expresando que la desigualdad no surgió por generación espontánea. Señalar que la desigualdad es responsabilidad de los políticos y de sus políticas compromete al Estado, a los gobiernos (en todos sus niveles) a las diversas organizaciones, empresas, instituciones (como la justicia, la universidad, los organismos científicos) que participan en su diseño y ejecución y a los organismos internacionales que las promueven, financian y controlan su desempeño. Todos actores que, por distintas razones, se benefician con la inequidad social. Aquí faltan también mayores 
identificaciones, pero es por este sendero por donde tenemos que transitar para identificar al poder y sus modalidades y mecanismos dirigidos a garantizar su proceso de acumulación.

Samir Amin (2011) -en sentido opuesto al que plantean las propuestas de desarrollo, y en los confines del documento de la CEPAL y, asimismo, de la intervención de Lagossugiere que hay que activar la audacia, para deconstruir el sistema existente y reconstruir sistemas nacionales que vayan hacia la desconexión de los intereses exclusivos de los monopolios imperialistas. Nos estimula a favor de un cambio de rumbo, de mentalidad y a pensar una globalización basada en la negociación y no en la subordinación. Y señala que esto implica desobedecer las reglas impuestas por las instituciones y estructuras de poder:

\begin{abstract}
Este momento nos ofrece la oportunidad histórica de ir mucho más lejos; nos demanda como única y efectiva respuesta una audaz y atrevida radicalización en la formulación de alternativas capaces de movilizar trabajadores y pueblos. (...) Audacia significa que la izquierda radical de estas sociedades debe tener el coraje necesario para medir los retos que afronta y apoyar la continuación y radicalización de las necesarias luchas actualmente en marcha (cursiva nuestra).
\end{abstract}

\title{
Crecimiento y desigualdad en América Latina durante la última década
}

Las reiteradas interpretaciones (pasadas y actuales) acerca del desarrollo latinoamericano y las respectivas propuestas para pasar de subdesarrollo al desarrollo gestadas desde los sectores de poder dominante se tornan insostenibles cuando revisamos información empírica sobre estos procesos. ${ }^{8}$

Precisamente, trabajaremos con indicadores agregados (PBI, desigualdad de ingresos, e índice de Gini) a partir de información (social y económica) producida por CEPAL. Es decir, por un organismo internacional que procesa datos agregados provenientes de los distintos gobiernos latinoamericanos. Este material nos va a permitir aplicar una mirada global y comparable de estos procesos entre países y desde una perspectiva de mediano plazo. ${ }^{9}$

AL creció entre 2003 y 2011 a una tasa promedio en torno al 5\% anual (medida por el incremento del producto bruto interno -PBI-Cuadro $1^{10}$ ). Expansión productiva 
CUADRO 1: América Latina y el Caribe. Tasas de variación anual del producto interno bruto total 1980-2011 y proyección 2012(en porcentajes, países seleccionados, promedio período 1980-1990 y variación anual 1990-2012).

\begin{tabular}{|c|c|c|c|c|c|c|c|c|c|c|c|c|c|c|c|c|c|c|}
\hline Países & \begin{tabular}{r|}
1980 \\
1990
\end{tabular} & 1990 & 1991 & 1992 & 1993 & 1994 & 1995 & 1996 & 1997 & 1998 & 1999 & 2000 & 2001 & 2002 & 2003 & 2004 & 2005 & 2006 \\
\hline Argentina & -0.7 & $-1,8$ & 10,6 & 9,6 & 5,7 & 5,8 & $-2,8$ & 5,5 & 8,1 & 3,9 & $-3,4$ & $-0,8$ & $-4,4$ & $-10,9$ & 8,8 & 9 & 9,2 & 8,5 \\
\hline Bolivia & 0.2 & 4,6 & 5,3 & 1,6 & 4,3 & 4,7 & 4,7 & 4,4 & 5 & 5 & 0,4 & 2,5 & 1,7 & 2,5 & 2,7 & 4,2 & 4,4 & 4,8 \\
\hline Brasil & 1.6 & $-4,4$ & 1 & $-0,5$ & 4,9 & 5,9 & 4,2 & 2,2 & 3,4 & 0 & 0,3 & 4,3 & 1,3 & 2,7 & 1,1 & 5,7 & 3,2 & 4 \\
\hline Chile & 3.0 & 3,7 & 8 & 12,3 & 7 & 5,7 & 10,6 & 7,4 & 6,6 & 3,2 & $-0,8$ & 4,5 & 3,4 & 2,2 & 3,9 & 6 & 5,6 & 4,6 \\
\hline Colombia & 3.7 & 4,3 & 2,4 & 4,4 & 5,7 & 5,1 & 5,2 & 2,1 & 3,4 & 0,6 & $-4,2$ & 2,9 & 1,7 & 2,5 & 3,9 & 5,3 & 4,7 & 6,7 \\
\hline Cuba & $\cdots$ & $-2,9$ & $-10,7$ & $-11,6$ & $-14,9$ & 0,7 & 2,5 & 7,8 & 2,8 & 0,2 & 6,2 & 5,9 & 3,2 & 1,4 & 3,8 & 5,8 & 11,2 & 12,1 \\
\hline Ecuador & 1.7 & 2,7 & 5,2 & 1,5 & 0,3 & 4,9 & 1,1 & 2,8 & 3,3 & 1,7 & $-5,3$ & 4,2 & 4,8 & 3,4 & 3,3 & 8,8 & 5,7 & 4,8 \\
\hline México & 1.9 & 5,1 & 4,2 & 3,6 & 2 & 4,4 & $-6,2$ & 5,2 & 6,8 & 5 & 3,8 & 6,6 & 0 & 0,8 & 1,4 & 4,1 & 3,3 & 5,1 \\
\hline Paraguay & 3.0 & 3,1 & 2,5 & 3,4 & 3,9 & 3,7 & 5,5 & 0,4 & 3 & 0,6 & $-1,5$ & $-3,3$ & 2,1 & 0 & 3,8 & 4,1 & 2,9 & 4,3 \\
\hline Perú & -1.2 & $-5,4$ & 2,8 & $-0,4$ & 4,8 & 12,8 & 8,6 & 2,5 & 6,9 & $-0,7$ & 0,9 & 3 & 0,2 & 5 & 4 & 5 & 6,8 & 7,7 \\
\hline Uruguay & 0.0 & 0,3 & 3,5 & 7,9 & 2,7 & 7,3 & $-1,4$ & 5,6 & 5 & 4,5 & $-2,8$ & $-1,4$ & $-3,4$ & -11 & 2,2 & 11,8 & 6,6 & 4,3 \\
\hline Venezuela & $\begin{array}{l}-0.7 \\
\end{array}$ & 6,5 & 9,7 & 6,1 & 0,3 & $-2,3$ & 4 & $-0,2$ & 6,4 & 0,3 & -6 & 3,7 & 3,4 & $-8,9$ & $-7,8$ & 18,3 & 10,3 & 9,9 \\
\hline América Latina & 1.2 & $\mathbf{0 , 4}$ & 3,5 & 2,8 & 3,4 & 4,8 & $\mathbf{0 , 7}$ & 3,5 & 5,3 & 2,4 & 0,6 & 4,4 & $\mathbf{0 , 7}$ & 0,4 & 1,7 & 5,9 & 4,6 & 5,6 \\
\hline El Caribe & 1.1 & 1,9 & 0,1 & $-0,6$ & 0,8 & 2,5 & 3,2 & 3,5 & 3,6 & 3,4 & 4,2 & 3,7 & 2 & 3,5 & 6,1 & 3,7 & 3,6 & 7,6 \\
\hline
\end{tabular}

FUENTE: Elaboración propia a partir de datos de la CEPAL.

Observaciones: 1) Años 1990-2010 Anuario estadístico de América Latina y el Caribe, 2011, CEPAL, ONU. A precios constantes 2005 2) Promedio década 1980-1990: Informe estadístico 2003, Indicadores del desarrollo socioeconómico de América Latina y el Caribe (sobre la base de precios constantes 1990). 3) Año 2011 y 2012 (proyección):

http://www.eclac.org/prensa/noticias/comunicados/9/46989/Cuadro_informe_macroeconomico_1Q.pdf .

inédita, que no se daba desde los setenta, y que se reprodujo en casi todos los países latinoamericanos a lo largo de ocho años (si bien con diferencias entre sí y con fluctuaciones anuales). ${ }^{11}$

Sin embargo, este significativo crecimiento (incluso en términos comparativos a nivel mundial) se tradujo en acotadas mejoras de los indicadores promedio de bienestar de la población trabajadora en general. Es el caso del desempleo,que descendió durante el quinquenio de mayor crecimiento menos de cuatro puntos (del 11\% en 2003 al 7,4\% en 2008 como promedio regional),y de los salarios,que mejoraronmuy moderadamenteen un $1,5 \%$ anual promedio, lo que mantuvo la brecha salarial a favor de la mano de obra más calificada (CEPAL, 2010, p. 58, 161, 164).

Son conquistas que, por otro lado, se pierden al ritmo de nuevas crisis, como sucedió en 2009 cuando se modificaron rápidamente varios de los avances alcanzados en el quinquenio anterior. Más aún, cuando los sectores trabajadores son los que especialmente sufren los vaivenes de la "volatilidad" de la macroeconomía -dicho en términos de los economistas ortodoxos-(CEPAL, 2011, p. 167). Desde luego que aquí 
estamos hablando de valores promedio, sólo a los efectos de marcar tendencias, pero no olvidamos que al interior de AL hay importantes diferencias entre países. ${ }^{12}$

En este contexto, vale recordar que Argentina fue el país latinoamericano que más creció en esos años y además lo hizo en el marco de tres sucesivos gobiernos (Néstor Kirchner, 2003-2007, y Cristina Fernández, 2007-2011 y 2011-2015)identificados por su continuidad ideológico-política y por adscribirse a prácticas consideradas "progresistas"; en particular, en los aspectos asociados con la inclusión de los marginados y la defensa de una política de derechos humanos amplia.

Argentina, por ambas cuestiones -mayor crecimiento del PBI y políticas inclusivas- es un caso testigo para el análisis de las limitaciones de la relación crecimiento y desigualdad. Para ello recurriremos a los informes de coyuntura de CIFRA-CTA. ${ }^{13}$ Allí se reconoce el crecimiento operado. ${ }^{14}$ Pero también se señala que el mismo no se ha traducido en mejoras equivalentes para los sectores más postergados.

Específicamente, CIFRA-CTA (mayo 2011, p. 33) sostiene que el notorio crecimiento del PBI operado desde 2003 se tradujo en una mejora tan solo parcial de la estructura distributiva"15: "A pesar de la extraordinariaexpansión del nivel de empleo, lostrabajadores apropian en la actualidad unaporción inferior del ingreso que a comienzosde la década del noventa. Este procesoobedece al relativamente bajo incremento registrado en los salarios reales, en el marco de una de las fases de crecimiento económico más significativas de la historia de nuestro país" (cursiva nuestra).

Asimismo, afirman que se mantienen elevados niveles (en porcentajes)de pobreza e indigencia sin beneficiarse de las extraordinarias tasas decrecimiento: "Si bien se verificó una notoria disminución de la pobreza y la indigencia entre 2003 y 2006, desde 2007 el nivel de dichas variables disminuyó sólo levemente. A fines de 2010, la pobreza alcanzaba al 22,9\% de la población y la indigencia al 6,1\% de la misma, tras ocho años de intenso crecimiento económico"(CIFRA-CTA, mayo de 2011, p. 34, cursiva nuestra).

Además, a través de estos informes (CIFRA-CTA, mayo de 2011; octubre de 2011 y abril de 2012) puede entenderse por qué la polarización y la desigualdad no disminuyó sustancialmente y por qué, por el contrario, podría estar incluso aumentandoen los últimos meses. Según explican los autores, esto se vincula con la obtención de mayores 
ganancias por parte de la cúpula empresaria ${ }^{16}$ mientras aumentan las pérdidas de ingresos de los sectores sociales de menores recursos. A estos, el incremento de precios afecta en el poder adquisitivo de sus salarios, lo cual también sucede con los ingresos informales de los sectores precarizados.

En síntesis, durante los años de gran crecimiento, favorecido por un contexto sociopolítico de apoyo popular hacia el gobierno, se ha logrado una mejora en la distribución del ingreso aunque limitada. En el Cuadro 2 puede apreciarse esta situación para Argentina y países seleccionados de Latinoaméricadurante el período 1999$2010 .^{17}$

En Argentina se observa que la población urbana ${ }^{18}$ más pobre (la del $1^{\circ}$ quintil) en 1999 recibía 3,5\% del ingreso nacional mientras que la más rica (la del $5^{\circ}$ quintil) acumulaba el 58,5\% de dicho ingreso (más aún, dentro de estos el estrato superior -sólo 10\% de la población- concentraba el 43\%). ${ }^{19}$ En definitiva, y promediando, en 1999 había un 20\% más rico que tenía un ingreso casi 16,7 veces mayor que el 20\% más pobre (peor aún, el ingreso del $10 \%$ más rico era 36 veces mayor que el del $10 \%$ más pobre).

Esa situación se modificó muy poco a favor de los más pobres en 2010, quienes siguieron participando casi con el mismo porcentaje $(3,7 \%$, o sea que elevó su participación respecto a 1999 en sólo 0,2 puntos porcentuales). En cambio, la población más rica descendió su participación aunque en una magnitud no significativa: continuó recibiendo más de la mitad del ingreso nacional $(55,4 \%)$ pero tuvo un descenso de 3,1 puntos porcentuales respecto a 1999, perdido por el $10 \%$ más rico y ganado por los sectores medios, especialmente los de los quintiles de ingreso más alto. Es decir, si bien la diferencia entre el 20\% más rico y el 20\% más pobre disminuyó (pasando en 2010 a ser de casi 15 veces) esta caída no fue a favor de los más pobres sino de los mejor posicionados en las escalas medias.

Estos cambios en los ingresos y en la distribución (que son similares en varios países latinoamericanos) responden a la dinámica operada desde 2003 en el mercado de trabajo, a través de la expansión del empleo y el aumento de los puestos formales (así lo interpretan los trabajos de CIFRA-CTA para Argentina -y también los estudios de la CEPAL para toda AL-). Lo cual se asocia con que los que más ganaron fueron los sectores medios, más capacitados y de mayores ingresos. En cambio, los asalariados de 
CUADRO 2: Distribución del ingreso de las personas, en áreas urbanas y rurales de. América Latina(países seleccionados, en porcentajes).

\begin{tabular}{|c|c|c|c|c|c|c|c|c|c|}
\hline & & & \multicolumn{2}{|c|}{ Quintil 1 (más pobre) } & \multirow{2}{*}{ Quintil 2} & \multirow[t]{2}{*}{ Quintil 3 } & \multirow[t]{2}{*}{ Quintil 4} & \multicolumn{2}{|c|}{ Quintil 5 (más rico) } \\
\hline País & Área geográfica & Año & Decil 1 & Decil 2 & & & & Decil 9 & Decil 10 \\
\hline \multirow{2}{*}{ Argentina } & \multirow{2}{*}{ Urbana } & $1999^{\mathrm{a}}$ & 1,2 & & 2,3 & 7,3 & 11,7 & 19,1 & 15,6 \\
\hline & & $2010^{b}$ & 1,2 & & 2,5 & 8,1 & 12,7 & 20,1 & 15,7 \\
\hline \multirow{6}{*}{$\begin{array}{c}\text { Bolivia (Estado } \\
\text { Plurinacional de) }\end{array}$} & \multirow{2}{*}{ Nacional } & 1999 & 0,3 & & 1 & 5,9 & 11,5 & 20,2 & 17,3 \\
\hline & & 2007 & 0,4 & & 1,7 & 6,4 & 11,7 & 20 & 17 \\
\hline & \multirow{2}{*}{ Urbana } & 1999 & 1,3 & & 2,6 & 8,1 & 12,5 & 20 & 16,7 \\
\hline & & 2007 & 1,7 & & 2,7 & 8 & 12,4 & 19,6 & 16,3 \\
\hline & \multirow{2}{*}{ Rural } & 1999 & 0,4 & & 0,8 & 3,9 & 9,3 & 19,4 & 17,3 \\
\hline & & 2007 & 0,3 & & 1,1 & 5,5 & 10,7 & 18,6 & 19 \\
\hline \multirow{6}{*}{ Brasil } & \multirow{2}{*}{ Nacional } & 2001 & 0,6 & & 1,4 & 5 & 9 & 16,1 & 15 \\
\hline & & 2009 & 0,8 & & 1,9 & 6,5 & 11 & 18 & 15,2 \\
\hline & \multirow{2}{*}{ Urbana } & 2001 & 0,6 & & 1,5 & 5,4 & 9,2 & 16,3 & 15,2 \\
\hline & & 2009 & 0,9 & & 2 & 6,7 & 11 & 18 & 15,3 \\
\hline & \multirow{2}{*}{ Rural } & 2001 & 0,8 & & 1,9 & 6,3 & 10,7 & 18,6 & 15,5 \\
\hline & & 2009 & 0,9 & & 2,2 & 7,4 & 12,4 & 21,1 & 16,6 \\
\hline \multirow{6}{*}{ Chile } & \multirow{2}{*}{ Nacional } & 2000 & 1,2 & & 2,2 & 6,8 & 10,7 & 17,5 & 15,2 \\
\hline & & 2009 & 1,4 & & 2,7 & 7,8 & 11,7 & 18,4 & 15 \\
\hline & \multirow{2}{*}{ Urbana } & 2000 & 1,2 & & 2,3 & 7 & 10,9 & 17,7 & 15,3 \\
\hline & & 2009 & 1,5 & & 2,7 & 7,8 & 11,7 & 18,4 & 15,1 \\
\hline & \multirow{2}{*}{ Rural } & 2000 & 1,5 & & 2,9 & 8,5 & 12,5 & 18,2 & 13,9 \\
\hline & & 2009 & 1,7 & & 3,3 & 9,4 & 13,5 & 19,5 & 14,5 \\
\hline \multirow{6}{*}{ Colombia } & Nacional & 1999 & 0,8 & & 2,1 & 6,8 & 10,9 & 17,9 & 15,1 \\
\hline & Nacional & $2010^{c}$ & 0,8 & & 1,9 & 6,4 & 10,7 & 18,3 & 15,8 \\
\hline & Uthon & 1999 & 0,9 & & 2,2 & 6,8 & 11 & 18,1 & 15,5 \\
\hline & Urbana & $2010^{c}$ & 0,9 & & 2,2 & 6,9 & 11,3 & 18,6 & 15,7 \\
\hline & & 1999 & 0,9 & & 2,4 & 8,2 & 12,5 & 19,3 & 14,9 \\
\hline & Rural & $2010^{c}$ & 1 & & 2,5 & 8,7 & 13,6 & 20,6 & 15,5 \\
\hline & Nacional & 1999 & 1,2 & & 2,8 & 8,8 & 13,6 & 21,5 & 16,9 \\
\hline & Nacional & 2010 & 1,3 & & 2,7 & 8,4 & 12,8 & 20,5 & 16,8 \\
\hline Costa Bica & Urhana & 1999 & 1,5 & & 3 & 8,9 & 14 & 22,4 & 17,1 \\
\hline Custa nica & Uivana & 2010 & 1,5 & & 2,8 & 8,6 & 12,9 & 21 & 17,1 \\
\hline & Rural & 1999 & 1,2 & & 2,9 & 9,3 & 14,3 & 21,8 & 16,3 \\
\hline & & 2010 & 1,2 & & 2,7 & 8,8 & 13,5 & 20,5 & 15,8 \\
\hline & Nacional & 2004 & 1,3 & & 2,4 & 7,7 & 12,5 & 19,9 & 16,3 \\
\hline & & 2010 & 1,5 & & 2,7 & 8,4 & 12,9 & 19,9 & 16,1 \\
\hline Ecuador & Urbana & 1999 & 1,2 & & 2,6 & 7,7 & 11,8 & 19,2 & 15,7 \\
\hline & & 2010 & 1,6 & & 2,8 & 8,6 & 13 & 20,1 & 16 \\
\hline & Rural & 2004 & 1,8 & & 3,1 & 9,8 & 14,7 & 22,3 & 16,3 \\
\hline & Kural & 2010 & 1,8 & & 3,4 & 10,2 & 15 & 21,9 & 15,6 \\
\hline
\end{tabular}


CUADRO 2 (continuación): Distribución del ingreso de las personas, en áreas urbanas y rurales de. América Latina(países seleccionados, en porcentajes).

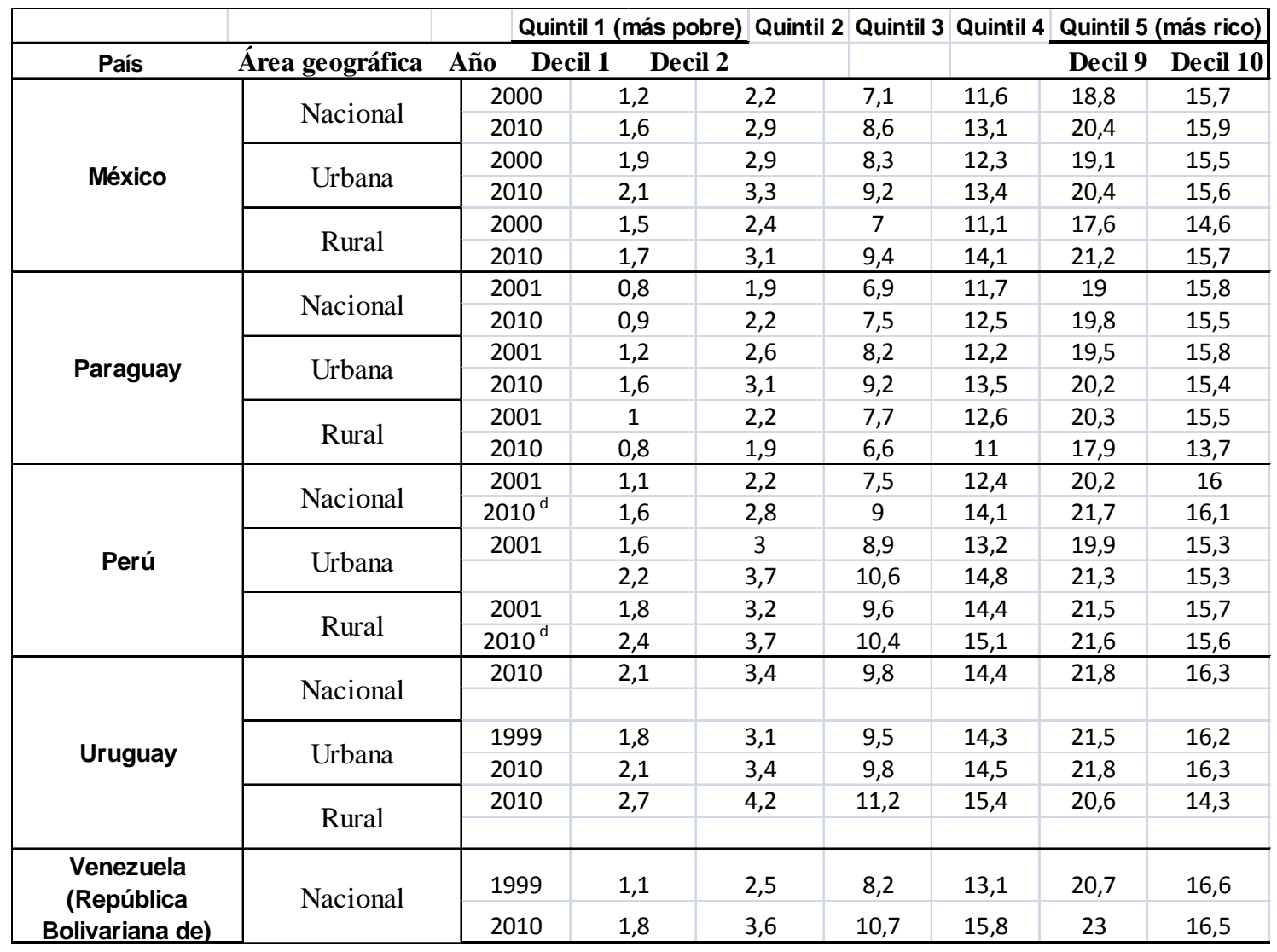

FUENTE: Elaboración propia a partir de CEPAL, Anuario Estadístico de América Latina y el Caribe, 2011, ONU.

Notas: ${ }^{a}$ Veintiocho aglomeraciones urbanas. ${ }^{\mathrm{b}}$ Treinta y una aglomeraciones urbanas. ${ }^{\mathrm{c}}$ A partir de 2002 el diseño muestral de la encuesta hace que las cifras para las zonas urbanas y rurales no sean estrictamente comparables con las de años anteriores. ${ }^{\mathrm{d}}$ Las cifras desde 2004 en adelante no son estrictamente comparables con las anteriores, debido a cambios metodológicos efectuados por el INEI.

menor nivel, los informales y los carenciados tuvieron una muy lenta recuperación de su participación en el ingreso nacional.

En el caso de Argentina, por ejemplo, el problema de esta lenta recuperación en medio de un gran crecimiento no es menor, porque existió la oportunidad de un importante crecimiento que no pudo aprovecharse, aún con un gobierno considerado "progresista", para que los sectores asalariados en conjunto recuperaran la participación en el PBI que perdieron en las dos décadas anteriores de nulo y limitado crecimiento. ${ }^{20}$

Lo importante para destacar es que tampoco las estrategias de ingresos e inserción laboral que fueron aplicadas, lograron posicionar a este sector con fortalezas y logros de carácter más permanente, estructural y menos voluntarista, de modo que la irrupción de 
nuevas crisis y recesiones no los regrese rápidamente a la situación previa. Para ello se requeriría un cambio en los patrones de conformación del ingreso que se ligan fundamentalmente con mayores capacidades y especialidades a nivel de la educación y el conocimiento. Y que a su vez también implican mejoras en el acceso a la vivienda, la salud y a las infraestructuras de servicios en general.

Nos referimos a un tipo de política de inclusión más estructural y menos ligada a la asistencia y la seguridad social. Es un cambio que especialmente sería esperable que suceda en los países que han tenido y siguen teniendo gobiernos con tendencias progresistas o más populares (como serían Argentina, Brasil, Bolivia, Ecuador, Uruguay y Venezuela).

Por cierto que en estos años de crecimiento se han dado en cada país mejoras sociales para los más carenciados. Reproducimos abajo el Gráfico 1 (CEPAL, 2010, p. 188) donde se observa que entre 2002 y 2008 hubo un descenso de la pobreza de 11 puntos porcentualesen AL. Es decir, cayó 25\%, aunque los pobres continuaron siendo muchos (un tercio -33\%- de la población total). Conjuntamente, bajó la indigencia en casi $34 \%$ y el desempleo en 33\%, mientras el empleo aumentó cerca de un 6\%. Todo esto junto implicó que la desigualdad disminuyera un $5 \%$ (índice de Gini). ${ }^{21}$

Sin embargo, como señalamos para el caso de Argentina, también en AL otros datos indican que el mejoramiento en la calidad y nivel de vida de la población de menores recursos no se gestó bajo parámetros estructurales dirigidos a enfrentar renovadas situaciones de crisis. Aquí también faltaron mejoras asociadas con avances en el ámbito de la educación, el conocimiento y las infraestructuras respectivas (CEPAL, 2011, p.189). Pero, asimismo, tampoco tuvieron, especialmente para el sector más postergado (que representa entre el 20\% y el 30\% -o más- de la población, según los casos) la amplitud y profundidad que podía esperarse en relación a la significativa y continuada expansión del PBI operada, casi generalizadamente en AL durante esos años.

Volviendo al cuadro 2 observamos que en todos los países hubo una mejoría entre 1999 y 2010 en la distribución de ingresos (aunque, en general, en magnitudes acotadas); que alcanzó especialmente a los sectores medios con mejor educación y formación general. En todos los casos, el $20 \%$ más pobre tuvo un beneficio menor. 
GRAFICO 1: América Latina y el Caribe: pobreza, indigencia, empleo, desempleo y coeficiente de Gini, alrededor de 2002 y $\mathbf{2 0 0 8}^{\text {a }}$ (en unidades de Gini por 100 y porcentajes).

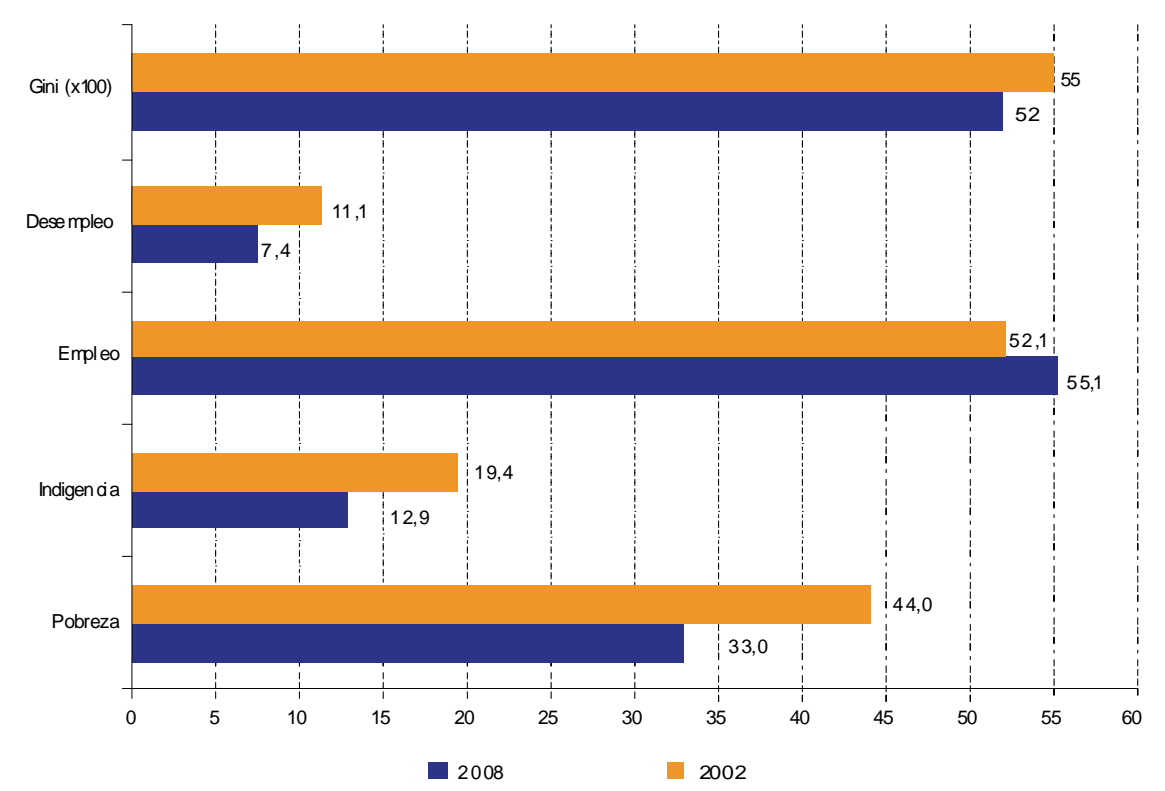

FUENTE: Comisión Económica para América Latina y el Caribe/Organización Internacional del Trabajo (CEPAL/OIT), "Crisis y mercado laboral”, Boletín CEPAL/OIT: Coyuntura laboral en América Latina y el Caribe, $\mathrm{N}^{\circ} 1$, Santiago de Chile, junio de 2009.

Nota: ${ }^{a}$ El período 2002 corresponde a la encuesta disponible más cercana a dicho año, y 2008 a las encuestas disponibles entre2007 y 2008. En lo referente a desempleo y empleo, se trata de la tasa urbana correspondiente a América Latina y el Caribe.

Venezuela es el país que logró la mejor distribución de ingresos entre esos años: en 2010, el 10\% más rico participaba con menos del 30\% de los ingresos. ${ }^{22}$ También es el país donde se dio, entre 1999 y 2010, la mayor disminución de participación del 20\% más rico en los ingresos (-9,2 puntos porcentuales). Caída que pasó a beneficiar claramente a los sectores medios, mientras el 20\% más pobre sólo aumentó su posición en 1,8 puntos porcentuales.

El más desigual, en relación a la magnitud de ingresos controlada por el 10\% más rico, es Brasil. En 2009, este 10\% más rico controlaba el 46,5\% de los ingresos nacionales (aunque corresponde decir que esta distribución mejoró sensiblemente respecto a 2001: cuando ese $10 \%$ disponía del $52,8 \%$ del ingreso nacional). ${ }^{23}$

Y si tomamos el 20\% más rico, los países más desiguales en 2010 fueron Brasil y Colombia: en ambos,este $20 \%$ disponía del $62 \%$ de los ingresos. Pero vale señalar que la diferencia importante entre estos dos es que Brasil viene aplicando políticas que están 
mejorando esta desigualdad preexistente. ${ }^{24}$ En cambio, Colombia mantiene la misma desigualdad de una década atrás.

Esta situación que estamos describiendo también la podemos observar a partir de los índices de desigualdad (índices de Gini) para igual período (Cuadro 3). ${ }^{25}$ En todos los países latinoamericanos (excepto Venezuela, Uruguay, Costa Rica y, en 2010, México y Perú) sus indicadores de desigualdad superan el 0,5. Venezuela tuvo en 2010 el índice nacional más bajo $(0,39)$ de toda AL.

Es de interés detenerse en algunos cambios operados en este indicador en el período que estamos analizando. Entre 1999 y 2010, Venezuela mejoró la igualdad, pues su índice de desigualdad disminuyó un 21\% (también cayó en México un 11\% y en Brasil casi un 10\%). Para 2010, Venezuela era el país menos desigual en términos de ingresos de AL y el único con un índice por debajo de 0,4. Para esa misma fecha, México alcanzó una baja significativa en su desigualdad de ingresos, en particular en la referida al ámbito rural (-19\%). A su vez, el logro de Brasil en la disminución de su desigualdad le permitió dejar de encabezar la lista de los más desiguales en ingresos. Y aunque ahora comparte ese lugar con Colombia, está comparativamente mejor, porque su tendencia se muestra declinante, mientras que en Colombia la desigualdad se ha agravado respecto a 1999 (con un aumento del 1\%).

Otras mejoras hacia una mayor igualdad de ingresos se reflejan en caídas del índice deGini del 7\% en Chile y Ecuador (aunque en este caso mide sólo población urbana) y de $5 \%$ en Argentina (también sólo población urbana). ${ }^{26}$

Concluyendo, las tendencias hacia una mayor igualdad en la distribución de ingresos no fueron sustantivas (aunque desde luego, y como siempre, depende del cristal con que se mire). En primer lugar, porque sigue existiendo una enorme brecha en todos estos países (excepto Venezuela, y quizás también se pueda agregar Uruguay). Y, en segundo lugar, porque si bien hubo casos de cambios positivos que deben subrayarse (como sucedió en Brasil) corresponde recordar que todo esto se dio durante el lapso de la década (once años) de mayor crecimiento de AL de las últimas tres décadas (en particular, en algunos países, y especialmente en Argentina). 
CUADRO 3: Indice de Gini, en áreas urbanas y rurales ${ }^{\mathrm{a}}$ de América Latina (países seleccionados, valores entre 0 - equidad absoluta- y 1 -inequidad absoluta-).

\begin{tabular}{|c|c|c|c|c|}
\hline País & Año & Nacional & Urbana & Rural \\
\hline \multirow{2}{*}{ Argentina } & $1999^{\mathrm{b}}$ & $\ldots$ & 0,539 & $\ldots$ \\
& $2010^{\mathrm{c}}$ & $\ldots$ & 0,509 & $\ldots$ \\
\hline \multirow{2}{*}{ Bolivia (Estado Plurinacional de) } & 1999 & 0,586 & 0,504 & 0,640 \\
& 2007 & 0,565 & 0,499 & 0,599 \\
\hline \multirow{2}{*}{ Brasil } & 2001 & 0,639 & 0,628 & 0,581 \\
& 2009 & 0,576 & 0,569 & 0,523 \\
\hline \multirow{2}{*}{ Chile } & 2000 & 0,564 & 0,558 & 0,511 \\
& 2009 & 0,524 & 0,524 & 0,466 \\
\hline \multirow{2}{*}{ Colombia } & 1999 & 0,572 & 0,564 & 0,525 \\
& 2010 & 0,578 & $0,555^{\mathrm{d}}$ & $0,494^{\mathrm{d}}$ \\
\hline \multirow{2}{*}{ Costa Rica } & 1999 & 0,473 & 0,454 & 0,457 \\
& 2010 & 0,492 & 0,477 & 0,483 \\
\hline \multirow{2}{*}{ Ecuador } & 1999 & $\ldots$ & 0,526 & $\ldots$ \\
& 2010 & 0,495 & 0,485 & 0,420 \\
\hline \multirow{2}{*}{ México } & 2000 & 0,542 & 0,493 & 0,553 \\
& 2010 & 0,481 & 0,456 & 0,450 \\
\hline \multirow{2}{*}{ Paraguay } & 2001 & 0,558 & 0,511 & 0,524 \\
& 2010 & 0,533 & 0,468 & 0,586 \\
\hline \multirow{2}{*}{ Perú } & 2001 & 0,525 & 0,477 & 0,439 \\
& $2010^{\mathrm{e}}$ & 0,458 & 0,408 & 0,403 \\
\hline \multirow{2}{*}{ Uruguay } & 1999 & $\ldots$ & 0,440 & $\ldots$ \\
& 2010 & 0,422 & 0,422 & 0,384 \\
\hline \multirow{2}{*}{ Venezuela (República Bolivariana de) } & 1999 & 0,498 & $\ldots$ & $\ldots$ \\
\hline \multirow{2}{*}{} & 2010 & 0,394 & $\ldots$ & $\ldots$ \\
\hline
\end{tabular}

FUENTE: Elaboración propia a partir de CEPAL, Anuario Estadístico de América Latina y el Caribe, 2011, ONU.

Notas: ${ }^{\mathrm{a}}$ Incluye a las personas con cero ingreso. ${ }^{\mathrm{b}}$ Veintiocho aglomeraciones urbanas. ${ }^{\mathrm{c}}$ Treinta y una aglomeraciones urbanas. ${ }^{\mathrm{d}} \mathrm{A}$ partir de 2002 el diseño muestral de la encuesta hace que las cifras para las zonas urbanas y rurales nosean estrictamente comparables con las de años anteriores. ${ }^{e}$ Las cifras desde 2004 en adelante no son estrictamente comparables con las anteriores, debido a cambios metodológicos efectuados por el INEI.

Desde esta mirada, y previendo que las crisis del mundo capitalista vienen tornándose cada vez más repetitivas, reaparece repetidamente la pregunta: ¿es posible modificar esta situación que se arrastra desde tantas décadas atrás y aún siglos bajo el sistema de mercado dominante? Evidentemente, pareciera que un desarrollo más igualitario no se corresponde ni ahora, ni en el pasado, ni en el futuro, con el armazón del modelo capitalista en el que cual estamos inmersos. 


\section{Desigualdad y desarrollo en América Latina: conceptos y realidades ¿en oposición? o ¿complementarios?}

Cuando la desigualdad aparece con su presencia insistente a lo largo de la historia de las economías latinoamericanas desde la crisis del orden colonial, cuando incorporamos en nuestra percepción más profunda su continuada permanencia, siglos de profundas inequidades sociales y de altos porcentajes de poblaciónpobre, sin trabajo, ni atención en salud, educación y vivienda y aún, pasando hambre,los discursos sobre las potencialidades de desarrollos alternativos, las políticas que supuestamente tenderían a la igualación y a la reparación de tantos atropellos a la cualidad humana, no tienen argumentación ideológica desde la cual sostenerse.

El hecho que en AL se acepte y conviva por décadas con los más altos niveles de desigualdad de ingresos pareciera indicarnos que, para el capital,esto constituye una reserva, un crédito social. Porque, de algún modo, dilata la emergencia de las crisis del capitalismo, ya que permite que la obtención de plusvalía y la explotación del capital pueda avanzar hacia límites más extremos. AL ofrece, así, ventajas para las inversiones de capital y especialmente para las de mayor riesgo social y ambiental.

La desigualdad se torna, por lo tanto, funcional, "natural", porque permanece a lo largo de siglos y, aparentemente, no resulta disruptiva, ni insostenible social, política e institucionalmente para el funcionamiento del "modelo de desarrollo".

Pero entonces, si la exclusión y la vulnerabilidad de AL, junto con la riqueza y los lujos exacerbados, son parte de la propia consecución del modelo capitalista global, necesitamos reflexionar acerca del rol de los Estados-nación y de las respectivas burguesías y oligarquías nacionales. Porque aparece que tanto los estados como las burguesías no buscan, ni quieren modificar y/o traspasar los límites que se imponen o se acuerdan con las instituciones de poder hegemónico nacionales e internacionales.

¿No es esto colonialidad del poder? ¿Por qué AL no se ha desacoplado de este proceso, transformando radicalmente su sociedad esperanzada en el "desarrollo" del capitalismo latinoamericano en una sociedad dispuesta a construir, definir y crear su propia autonomía soberana?

Más aún cuando su deuda social es enorme en tanto, con una población estimada para 2012 (CEPAL, 2011, p. 23) de 603 millones de personas, AL y el Caribe tiene:

a.En situación de hambre, 52.2 millones de personas (distribuidas diferencialmente según los países). ${ }^{27}$

Geo UERJ - Ano $14, n^{\circ} .23$, v. 2, $2^{\circ}$ semestre de 2012 p. 717-745

ISSN: 1415-7543 E-ISSN: 1981-9021

http://www.e-publicacoes.uerj.br/index.php/geouerj 
b. En situación de pobreza, casi 190 millones de personas. ${ }^{28}$

c. En situación de indigencia, 74 millones de personas que no pueden alimentarse adecuadamente, porque su ingreso es inferior al costo de una canastabásica de alimentos (CEPAL, 2011: 66 y141).

¿Sonhumana y socialmente sostenibles flagelos como el hambre, la indigencia, la pobreza, en beneficio de una desigualdad funcional al desarrollo que asegurabuen nivel de vida y de consumo para unos pocos privilegiados?

Bajo este razonamiento, recordamos la incisiva pregunta que oportunamente se formulara Bolívar Echeverría (2001, p. 49-50):

\footnotetext{
“¿Por qué la vida económica de los estados latinoamericanos, después de más de cien años de dependencia y colaboración con el desarrollo del sistema capitalista, no ha llegado a ser absorbida por él ni ha podido tampoco generar condiciones para una reproducción autosustentable de la propia acumulación de capital?".
}

Creemos que esta cuestión no está desligada del análisis aquí realizado, que requiere responder a esta otra pregunta: ¿Por qué AL puede sostenerse dentro del desenvolvimiento capitalista con una distribución de ingresos y condiciones de vida más agudamente desigual que en cualquier otra parte del mundo?

O dicho de otro modo, sila aguda polarización latinoamericana (con sus dos extremos: sectores sociales muy carenciados, por un lado, y muy enriquecidos y poderosos, por el otro) es socialmenteinsostenible en varios de los países del primer mundo, entonces esto estaría indicando que: ¿AL tiene mayor capacidad -política, social y cultural- para absorber sus niveles de inequidad? ¿Por qué? Y ¿a qué responde?Algunas hipótesis y preguntas surgen al respecto.

- ¿Será que la aceptación y permanencia de un modelo tan desigual está más ligada a valores subjetivos y simbólicos de parte de la mayoría de la sociedad latinoamericana? Por ejemplo, ¿el carismático y también energizante discurso sobre el "desarrollo" ha legitimado la indiferencia ante tanta vulnerabilidad social? ¿La cultura se ha estructurado simbióticamente en torno a la creencia acerca de la potencialidad de las políticas de desarrollo para transformar la realidad latinoamericana? De ser así, estamos ante un paradigma que ha permeado e impregnado cual dogma y masivamente la conciencia social. Y ello explica el mantenimiento y la renovación de la confianza y de la esperanza hacia un futuro mejor (siempre alejado, siempre más allá) y con potencialidad para cambiar tantas inequidades.

Geo UERJ - Ano 14, no. 23, v. 2, $2^{\circ}$ semestre de 2012 p. 717-745

ISSN: 1415-7543 E-ISSN: 1981-9021

http://www.e-publicacoes.uerj.br/index.php/geouerj 
- Asimismo, la sociedad, ¿conoce que repetidamente se instalan nuevos planes, propuestas y políticas? ¿Sabe qué ha habido una permanente oferta de proyectos y programas que fueron presentados como propuestas dirigidas a superar el colonialismo, el subdesarrollo, la dependencia, el Tercer Mundo y las diferentes expresiones de marginalidad social? ¿Ha sido informada que sus resultados no han respondido a los objetivos planteados originalmente? Posiblemente todo esto no se conozca con claridad en forma socialmente generalizada. Porque estos procesos no se transparentan, ni se difunden y tampoco se informan; más bien se disfrazan o maquillan, único modo para el 'poder' de sostener su hegemonía y mantenerse aliado con el poder político de turno.

- Sin embargo, lo anterior no se da taxativamente en forma generalizada. En algunos territorios y para algunos sectores sociales, la población tiene experiencia de promesas e incumplimientosrepetidos en la aplicación de planes y proyectos. Cuando esto sucede, cuando se transmite de generación en generación, ¿qué esperan los más jóvenes ante una nueva propuesta? Paradójicamente, es frecuente que se renueve la esperanza. Reaparece la fe en que esta vez, seguramente, aquellas propuestas podrán constituirse en alternativas ciertas, eficientes y eficaces.Creemos que en este campo, el paso de los años y la herencia cultural entre generaciones suele jugar a favor de la dominación y del poder porque: (i)para los adultos mayores es muy factible que aquellos hechosya hayan sido olvidados y, paralelamente, (ii) para muchos jóvenes la experiencia no vivida, la experiencia de sus padres y abuelos, no determina su derrotero futuro.

- Por último, sin duda, también hay simultáneamente, actores y sujetos con profundo esclarecimiento de todas estas manipulaciones. Ellos son, en general, los que practican una participación política activa, los que se han capacitado desde los procesos de organización social, los que tienen como paradigma la solidaridad, los que por diferentes circunstancias acceden a mayor información y promueven su difusión. Son sujetos que se oponen a lo que amenaza su libertad, su creatividad y su raciocinio y que tienenvoluntad y capacidad para gestar renovadas y creativas respuestas locales dirigidas a enfrentar al modelo capitalista, a la exclusión, a la acumulación depredadora de vidas y ambiente. Son los que buscan construir otra realidad,impulsando renovadas perspectivas, desde los lugares donde habitan y trabajan junto y a la par de otros actores locales. Son sujetos con habilidad y/o capacidad para la acción que, defendiendo 
susdecisiones, ejercen 'poder' y transforman su territorio. En definitiva, son los que se rebelan, los que resisten..." (MANZANAL, 2007, p. 22).

Esto nos lleva a reconocer que, por un lado, hay una parte importante de la sociedad de AL (no necesariamente la que se beneficia con el modelo dominante) que confía y piensa que los problemas del capitalismo se resuelven con más capitalismo. Ello explicaría parcialmente la aceptación social de tan aguda y permanente desigualdad social. Pero, por otro, también hay un sector que se enfrenta y moviliza a favor de la instalación de un nuevo paradigma basado en la solidaridad y en la emancipación del modelo actual.

Diferentes experiencias sociales contradictorias, de apoyo y de resistencia,en territorios de América Latinadan cuenta de estas afirmaciones. Una de ellas sucede con el avance de las actividades ligadas a los commodities y a la minería, cuyo expansivo ciclo productivo (que interesa y recibe el beneplácito de muchos sectores sociales) convive conun accionar depredador de los recursos ambientales (generando la oposición de otros tantos sectores sociales). Mientras tanto yconjuntamente, ambos -commodities y minería- son responsables de la ampliación de ladesigualdad social. Por un lado, por sus importantes niveles de concentración económica resultante de su alta rentabilidad (que, en su mayor parte, no queda ni se reinvierte en estas latitudes). Y por otro, por la devastación ambiental y la marginación social consecuente.Alto enriquecimiento vs. escasa o nula ocupación es una constante. Producción extractiva y expansiva vs. contaminación y daños ecológicos es otra.

Finalmente, estas dos actividades también se asemejan por la resistencia socialdelos sectores que se oponen a la confiscación de los recursos ambientales. En la actualidad, en Argentina, los movimientos sociales más activos y contestatarios, los que han logrado mayor repercusión social, se encuentran en el ámbito de la lucha contra la minería a cielo abierto y contra la desposesión de los pobladores de sus tierras por el avance de la frontera agropecuaria.

\section{Reflexiones finales}

En definitiva, es importante comprender que la continuada construcción de alternativas para una nueva e idealista propuesta de desarrollo -la planificación del desarrollo, el desarrollo local, endógeno, territorial, humano, ambientalmente sostenible, 'la hora de la igualdad', etc.- es un instrumento del poder hegemónico para diseñar utopías que

Geo UERJ - Ano 14, no. 23, v. 2, $2^{\circ}$ semestre de 2012 p. 717-745

ISSN: 1415-7543 E-ISSN: 1981-9021

http://www.e-publicacoes.uerj.br/index.php/geouerj 
mantengan a la población idealizando un futuro esperanzador, de cuyos fracasos posteriores nadie se va a hacer cargo; así sucedió y seguirá sucediendo bajo esta lógica de desarrollo dominante ampliamente aceptada.

La historia nos muestra que AL brinda variadas oportunidades para garantizar la rentabilidad capitalista; recursos y riquezas aseguran la continuidad del proceso de acumulación. Pero también ofrece la aceptación social de una desigualdad instalada históricamente que no impide la acumulación, sino incluso quizás hasta la promueve.

En AL, la acumulación del capital pareciera operar dentro de un rango con límites más extendidos, aún durante las crisis. Es muy posible que todo esto se vincule con la renovada posibilidad de que una nueva utopía de desarrollo pueda volver a construirse... y la población a esperanzarse... Así ha sido en definitiva, si bien con altibajos, durante los últimos setenta años, por lo menos.

Lo señalamos más arriba en palabras de Esteva (1996): la mirada puesta en nuestro territorio para ejercer variadas prácticas de desarrollo (sea a causa del subdesarrollo, de las disparidades territoriales, de la limitada competitividad, del atraso cultural, etc.) es una demostración de poderde un estrecho sector de privilegio que nos indica lo que debemos hacer para "desarrollarnos".

Esta dominación ha impedido y desvalorizado la generación y producción de ideas y prácticas surgidas desde la propia creatividad y experiencia latinoamericana; lo cual se constituye en una carencia relevante del presente, dada la profunda debilidad del modelo dominante (expresada a través de la sucesión de crisis económico-financieras y las múltiples protestas sociales que se expanden por el Primer Mundo).

Pero para que se dé un nuevo marco de comprensión y, consecuentemente, de creación de otras realidades, necesitamos transformaciones radicales, dando respuesta $\mathrm{y}$ enfrentando con audacia al poder hegemónico en sus variadas modalidades, mecanismos de acción y expresiones territoriales. Efectivamente, estas situaciones también existen, aunque desde el ejercicio de la dominación y el poder se aproveche para acallarlas. Aparecen en distintos territorios de AL donde determinados actores y sujetos, junto a la población local plantean variadas formas de acción para frenar el accionar del poder hegemónico (nuestros estudios sobre el norte de Argentina, por ejemplo, muestran situaciones en este sentido que sin duda se repiten en toda AL - 
MANZANAL y VILLARREAL, 2009 y MANZANAL, ARZENO y NUSSBAUMER, 2007).

En definitiva, para que una transformación radical se dé, la sociedad civil, la población en general, tiene que adquirir una aguda noción crítica sobre los mecanismos, observables y no observables, de funcionamiento del modelo de mercado en el que estamos inmersosy del rol del Estado en la consecución del mismo. Una noción que obliga a un conocimiento sustantivo sobre el poder, descorriendo sus múltiples velos, descubriendo la información oculta.

Comprendiendo que es posible otra cultura, otra educación, no conformista, más solidaria, a favor de la autonomía y de la creatividad, será posible potenciar nuestra capacidad para descubrir alternativas por fuera del capitalismo, que tornen factible, económica y socialmente, el acceso del conjunto social a una calidad de vida superior y más igualitaria en la estructura distributiva del ingreso.

Necesitamos entender introspectivamente y en toda su dimensión que no es con recetas externas y renovadas, alejadas de la experiencia y de la historia latinoamericana, como lograremos transformar la realidad latinoamericana.

Nos emanciparemos cuando identifiquemos que nuestros derechos no están comprendidos en las creencias y en las instituciones de esta cultura dominante que, a través de la escuela, la universidad, las iglesias, la policía, la justicia, dominan nuestras mentes con sus concepciones y fundamentalismos funcionales al capitalismo y a la desigualdad social.

Producir otra educación y otra cultura debe ser nuestra meta. 


\section{BIBLIOGRAFÍA}

- AMIN, SamirAudacia, más audacia. Disponible en: http://alainet.org/active/51548. América Latina en Movimiento,ALAI. Acceso 30 de mayo 2012.

- CASTORIADIS, Cornelius. Reflexiones sobre el 'desarrollo' y la 'racionalidad' . En CASTORIADIS, Cornelius. El mito del desarrollo.Madrid:Kairós, 1980, 258p. p.183209.

- CEPAL. Informe estadístico 2003, Indicadores del desarrollo socioeconómico de América Latina y el Caribe.Santiago: Naciones Unidas, 2004. 83p.

- CEPAL. La hora de la igualdad. Brechas por cerrar, caminos por abrir.Santiago: Naciones Unidas, 2010, 290p.

- CEPAL. Anuario estadístico de América Latina y el Caribe, 2011.Santiago: Naciones Unidas, 2011, 217p.

- CEPAL. América Latina y el Caribe. Producto interno bruto total. Disponible en http://www.eclac.org/prensa/noticias/comunicados/9/46989/Cuadro_informe_macroeco nomico_1Q.pdf. Acceso 17 de julio de 2012.

- ECHEVERRÍA, Bolívar. Definición de la cultura. México DF:Itaca, 2001.

- ECHEVERRÍA, Bolívar. Entrevista de Javier Sigüenza.Cuadernos de Pensamiento Crítico LatinoamericanoNº 44.Buenos Aires:CLACSO-Página 12, 2011. p.1-4.

- ESCOBAR, Arturo. El 'postdesarrollo' como concepto y práctica social, en DANIEL, M. (Coordinador). Políticas de economía, ambiente y sociedad en tiempos de globalización, Caracas: Facultad de Ciencias Económicas y Sociales, Universidad Central de Venezuela, 2005.p. 17-31.

- ESTEVA, Gustavo. Desarrollo. En SACHS, W. (edit.) Diccionario del desarrollo. Una guía del conocimiento como poder.Perú:PRATEC, 1996. 383p. p. 52-79.

-GELMAN, Jorge. Introducción en GELMAN, Jorge (Coordinador).El mapa de la desigualdad en la Argentina del siglo XIX.Rosario,Prohistoria,2011, 405p. p.11-45.

- LASH, Scott y URRY, John. Economías de signo y espacio. Sobre el capitalismo de la pos organización.1 ed. Buenos Aires:Amorrortu, 1998, 465 p.

- MANZANAL, Mabel. Territorio, poder e instituciones. Una perspectiva crítica sobre la producción del territorio. En MANZANAL, Mabel. ARZENO, Mariana y NUSSBAUMER, Beatriz (Compiladoras).Territorios en construcción. Actores, tramas y gobiernos: entre la cooperación y el conflicto. Buenos Aires: CICCUS, 2007. 28p. p.15-50.

- MANZANAL, Mabel. Desarrollo, poder y dominación. Una reflexión en torno a la problemática del desarrollo rural en Argentina. En MANZANAL, Mabel y VILLARREAL, Federico(Organizadores).El desarrollo y sus lógicas en disputa en el norte argentino. Buenos Aires: CICCUS, 2010. p.270, p.17-44.

- MANZANAL, Mabel y VILLARREAL, Federico(Organizadores). El desarrollo y sus lógicas en disputa en el norte argentino. Buenos Aires: CICCUS,2010. p.270

- MANZANAL, Mabel, ARZENO, Mariana y NUSSBAUMER, Beatriz. (Compiladoras). Territorios en construcción. Actores, tramas y gobiernos: entre la cooperación y el conflicto.Buenos Aires:CICCUS, 2007. 284 p.

- QUIJANO, A. El fantasma del desarrollo en América Latina. Caracas: Revista Venezolana de Economía y Ciencias Sociales,v. 6, n² 2. p. 73-90. Mayo-Agosto2000.

- ROIG, Alexandre. El desarrollo como conflicto institucionalizado en Realidad Económica 237.Buenos Aires:IADE, p. 80-92. Julio-Agosto 2008.

- SACHS, Wolfang (Editor).Diccionario del desarrollo. Una guía del conocimiento como poder.Perú:PRATEC, 1996. 383p.

Geo UERJ - Ano 14, no. 23, v. 2, $2^{\circ}$ semestre de 2012 p. 717-745

ISSN: 1415-7543 E-ISSN: 1981-9021

http://www.e-publicacoes.uerj.br/index.php/geouerj 


\title{
SIGLAS
}

AFJP: Administradoras de Fondos de Jubilaciones y Pensiones

AL: América Latina

AUH: Asignación Universal por Hijo

BID: Banco Interamericano de Desarrollo

BM: Banco Mundial

CEPAL: Comisión Económica para América Latina

CIFRA-CTA: Centro de Investigación y Formación de la República Argentina - Central de Trabajadores de Argentina

FAO: Organizaciones de las Naciones Unidas para la Agricultura y la Alimentación

INDEC: Instituto Nacional de Estadísticas y Censos

OCDE: Organización para la Cooperación y el Desarrollo Económico

PBI: Producto Bruto Interno

ONU: Organización de las Naciones Unidas

\section{NOTAS FINALES}

\begin{abstract}
${ }^{1}$ Este artículo se enmarca en el contexto de los proyectos: PICT FONCyT-Agencia (2006 0188 y 2011 0836); UBACyT (2008 F056 y 2011 F154); y PIP Conicet (2009 1879 y 2012 0273), todos ellos dirigidos por Mabel Manzanal. Una versión anterior de este trabajo (titulada Poder y desarrollo. Dilemas y desafíos frente a un futuro ¿cada vez mas desigual?) aparece en Manzanal, Mabel y Mariana Ponce (Organizadoras), La desigualdad ¿del desarrollo?. Controversias y disyuntivas del desarrollo rural en el norte argentino, CICCUS, Buenos Aires, 2013, 320 p. ISBN 978-987-693-015-4.

${ }^{2}$ Mabel Manzanal es investigadora principal del Consejo Nacional de Investigaciones Científicas y Tecnológicas -Conicet- profesora titular de la Universidad de Buenos Aires -UBA- y Directora del PERT (Programa de Economías Regionales y Estudios Territoriales, del Instituto de Geografía, Facultad de Filosofía y Letras, Universidad de Buenos Aires -UBA).

3 Precisamente, algo propio de las dos etapas arriba señaladas es buscar la diferenciación entre crecimiento y desarrollo, sosteniendo que el crecimiento, per se, es desequilibrado y desigual, mientras que el desarrollo podría ser, según como se postule y dirija, más o menos equitativo. Desde nuestra perspectiva, el uso de esta distinción no es más que un nuevo eufemismo del poder que, de este modo y una vez más, sirve para ocultar el funcionamiento naturalmente desequilibrado del sistema capitalista en el cual estamos inmersos.

${ }^{4}$ Y el BID, durante 2010 y 2011, promovió la formulación de una estrategia para una política social favorable a la igualdad, documento que puede consultarse en http://idbdocs.iadb.org/wsdocs/getdocument.aspx?docnum=35432109

${ }^{5}$ Véase:http://www.eclac.cl/cgibin/getProd.asp?xml=/publicaciones/sinsigla/xml/7/5087/P5087.xml\&xsl= /tpl/p10f.xsl\&base=/tpl/top-bottom.xslt

${ }^{6}$ Desde el surgimiento del movimiento alter mundista a fines de 1999 en diferentes momentos y lugares, aparecen variadas y novedosas formas de oposición al sistema con métodos desconocidos hasta el presente a nivel mundial, como es el apoyo de las redes sociales e internet. Pero, además, se está dando en lugares impensados, como sucedió a comienzos de 2011 en el mundo árabe contra las dictaduras que, instaladas cual monarquías, habían sido inamovibles por décadas desde Túnez hasta Egipto. Luego aparecieron los jóvenes "indignados" en España, que se reprodujeron en Italia, Francia, Inglaterra -con muchas similitudes al "que se vayan todos" de Argentina de la crisis de 2001-2002 pero ahora en las estables y consolidadas democracias europeas-. Y estas movilizaciones continúan expandiéndose, repudiando cuestiones antes impensadas, como sucede con la protesta de los estudiantes en Chile por el costo de la educación en ese país y la de los jóvenes ocupantes de Wall Street por la corrupción y los recortes presupuestarios en Estados Unidos.

${ }^{7}$ Lagos agrega en su artículo otros referentes importantes reclamando por mayor igualdad, como el presidente del BID, Luis Alberto Moreno, quien afirma que es necesario "que la región cierre la brecha de
\end{abstract}

Geo UERJ - Ano 14, no. 23, v. 2, $2^{\circ}$ semestre de 2012 p. 717-745

ISSN: 1415-7543 E-ISSN: 1981-9021

http://www.e-publicacoes.uerj.br/index.php/geouerj 
desigualdades sociales". Fuente: Ricardo Lagos: "No hay más excusas para la desigualdad", Clarín, 7-082011 (cursiva nuestra).

${ }^{8}$ Corresponde advertir sobre las confusiones y problemas de interpretación que pueden generarse a raíz de las numerosas acepciones del término-concepto desarrollo, que en general no se aclaran. Más allá de su polisemia, señalada frecuentemente por distintos autores (entre ellos Roig, 2008, p. 60) hay cuestiones en este término-concepto que introducen mucha confusión. Porque desarrollo es tanto un "término" de uso común como un "concepto" producto de elaboración y discusión teórica (más o menos explicitada). Pero, además, como "término" puede referir a un proceso del pasado o del futuro, que debe ser deducido por quien lee o escucha y no se explicita. El interés de este trabajo se centra en los aspectos teóricos del concepto desarrollo, que bosquejamos en el apartado anterior y en Manzanal (2010, p. 25).Pero también usamos desarrollocomo término de uso común y no fácilmente sustituible. Precisamente, en esta oración que estamos referenciando, desarrollo está usado dos veces, como término y como concepto. Como término tiene que ver con el "acontecer" (social, político, económico y cultural). "Acontecer" que frecuentemente se asocia con progreso, pero también puede identificarse con la evolución y/o los cambios (no siempre visualizados como progreso). Pero debe tenerse presente que, además, este término-concepto puede referirse al pasado o al futuro. Precisamente, en la oración referenciada, en la primera mención, desarrollo refiere al devenir histórico, pasado, y en la segunda se vincula con el futuro, con lo que se espera.

${ }^{9}$ Vale aclarar que tenemos en cuenta en el análisis que estamos trabajando con información seleccionada y procesada por un organismo multilateral funcional a los intereses de las propuestas de desarrollo que han dominado en AL. Ello implica tomar recaudos al momento del análisis y de la elaboración de las conclusiones respectivas.

${ }^{10}$ Este cálculo promedio exceptúa la recesión de 2009 (resultante de la crisis mundial de 2008-2009). Puede observarse en el Cuadro 1 que, a partir de 2003-2004, AL inició un crecimiento más regular y sostenido y a mayores tasas que en los noventa (salvo ciertas excepciones dadas en algunos años o en determinados países -como la regular expansión de Chile en ese período). Entre 2003 y 2011 (exceptuando 2009, que refleja una caída resultante de la crisis mundial de 2008-2009),AL creció a una tasa promedio del 4,7\% anual (3,5\% agregando 2009) y las variaciones entre países van desde Argentina,con el 8,6\% promedio anual (7,8\% incluyendo 2009), a México,con un promedio anual de 3,5\% (1,9\% incluyendo 2009).Por su parte,Brasil tuvo un menor crecimiento promedio anual (4,4\% y $3,6 \%$ sumando 2009) respecto al de Argentina, aunque más regular, ya quedesde 1991 no pasó por ninguna retraccióny, en cambio, Argentina tuvo cuatro años seguidos de recesión desde 1999 con una notoria caída en $2002(10,9 \%)$.

${ }^{11}$ Corresponde mencionar que en lo que sigue trabajaremos con datos del anuario estadístico de la CEPAL 2011para los países de AL. Y que éste utiliza, a su vez, la información proveniente de los sistemas de cuentas nacionales de cada país. Los análisis que aquí se realizan parten de considerar confiable dicha información, aunque no desconocemos la existencia de cuestionamientos acerca de la manipulación de los mismos de parte de algunos gobiernos que modificarían sus estadísticas para reflejar resultados más satisfactorios de su gestión. Tampoco podemos ignorar que detrás de estas cuestiones se esconde, asimismo, una disputa de poder que resulta imposible soslayar cuando se está trabajando con datos producidos por los propios países. Sin embargo, dado el tipo de análisis que aquí realizamos (a nivel de grandes números, agregado, comparativo ypromediando tendencias de largo plazo) consideramos que los desvíos que pueden darse van a resultar menores y, a veces, imperceptibles para la presente indagación.

${ }^{12}$ La CEPAL (2011, p. 202) construye tres grupos de países según las brechas de bienestar. Los de menor brecha tienen un PIB más alto, menores tasas de dependencia demográfica (mejor relación etaria entre población productiva y dependiente), mercados de trabajo menos informales y con mayor seguridad social, mayor cobertura pública de los servicios de salud (menor proporción de gasto de bolsillo), menores niveles de pobreza e indigencia y un gasto público social no sólo superior en monto total per cápita, sino también como porcentaje del PIB. En la medida que nos movemos hacia países con menor desarrollo relativo, todos estos parámetros se desplazan hacia situaciones más críticas. Al primer grupo pertenecen Argentina, Brasil, Chile, Costa Rica, Panamá y Uruguay; al segundo, Colombia, México y Venezuela, y al tercero, los restantes países latinoamericanos.

${ }^{13}$ Centro de Investigación y Formación de la República Argentina de la Central de Trabajadores de Argentina. Utilizamos esta fuente porque nos resulta confiable. Y además, porque sus consideraciones contrarias a algunas prácticas y políticas públicas no pueden ser re-interpretados,desde el gobierno o sus partidarios, como una postura opositora. Por el contrario, CIFRA-CTA es mayoritariamente considerada

Geo UERJ - Ano 14, nº 23 , v. 2, $2^{\circ}$ semestre de 2012 p. $717-745$

ISSN: 1415-7543 E-ISSN: 1981-9021

http://www.e-publicacoes.uerj.br/index.php/geouerj 
“oficialista", porque concuerda con buena parte de las políticas públicas actuales. De todos modos, se trata de un centro que mantiene independencia en sus análisis, lo que se evidencia en sus informes de coyuntura con posiciones críticas respecto a la política pública y a su ejecución. Precisamente, una de ellas es la falta de credibilidad de los índices del INDEC. Lo que hace que CIFRA-CTA no utilice estos indicadores sino que aplique un índice promedio de institutos de estadísticas provinciales. Todo esto nos sugiere que el uso del calificativo "oficialista", bajo su connotación despectiva, está dirigido a desautorizarsu accionar y sus análisis (en un contexto de pronunciado enfrentamiento entre el gobierno,por un lado, y la oposición y los medios hegemónicos,por otro).

${ }^{14}$ En mayo de 2011 identificaban como logros: a) las elevadas tasas de crecimiento económico, tanto en términos históricos como regionales, b) la consolidación de un proceso de crecimiento centrado en el desarrollo de los sectores productores de bienes, c) el desaliento a las inversiones especulativas que caracterizaron a la economía argentina durante la hegemonía neoliberal, d) la reversión del proceso de desindustrialización vigente en nuestro país desde mediados de los setenta, e) la elevación sensible de la inversión y su peso en el producto, f) la obtención de un superávit comercial elevado, g) la reversión del déficit estructural que presentaron las finanzas públicas a lo largo de las últimas décadas, h) la disminución significativa del endeudamiento externo del sector público, i) la creación de más de cuatro millones de puestos de trabajo, quebrando de esta forma casi tres décadas de precarización en el mercado laboral, j) la reducción de las tasas de desocupación y subocupación a un dígito, k) el aumento sensible del empleo registrado, disminuyendo la incidencia del empleo precario, 1) la re-estatización de las AFJP y la ampliación de la cobertura del sistema previsional a más de dos millones de nuevos jubilados, m) la instrumentación de la Asignación Universal por Hijo (AUH) -históricamente demandada desde la CTA (CIFRA-CTA, mayo 2011, p. 35).

15 Por mejor estructura distributiva los autores entienden: incremento de la participación de los asalariados en el PBI, por ejemplo, a través de la generación de más puestos de trabajo y de la recuperación relativa de los salarios.

${ }^{16}$ En los informes CIFRA-CTA se explica este proceso de acrecentamiento del poder de los sectores más favorecidos y enriquecidos con mayor detalle. Por un lado, sostienen que se ha dado una continuidad y también una profundización de la extranjerización de la economía que favorece la fuga de capitales a través de una mayor remisión de utilidades y dividendos al exterior.También se refieren a los elevados niveles de ganancia de las empresas que conforman la cúpula empresaria, afirmando que son incluso superiores a los de la etapa de la convertibilidad.En CIFRA-CTA (octubre de 2011: 9) se señala: "la tasa de rentabilidad tuvo un sensible aumento en la pos-convertibilidad, ubicándose en el promedio de 20032010 en 8,5\%, mientras que en el período 1991-2001 había promediado el 3,1\%". A favor de esta concentración de la riqueza también opera la falta una reforma fiscal progresiva y la escasa decisión política para modificar el sistema de entidades financieras heredado desde la dictadura.

${ }^{17}$ En realidad, los períodos no son idénticos para todos los países, aunque se aproximan (depende de las diferencias en los años de encuestas y censos). En el caso de Argentina, la base 1999 puede interpretarse que "morigera" los cambios positivos y los logros del gobierno de Néstor Kirchner y Cristina Fernández, ya que si se parte de un año base de menor actividad económica (como 2002, año de la crisis) el crecimiento en relación a la distribución del ingreso a partir de 2003 sería mayor (porque la peor etapa de esta distribución fue la de la crisis de 2001-2002, cuando el PBI se redujo en 4,4\% en 2001 y en $10,9 \%$ en 2002 -Cuadro 1). De todos modos, 1999 indica el comienzo de la recesión que se prolongó por cuatro años y que culmina en 2002 (la caída del PBI en 1999 fue de 3,4\%). Por lo cual consideramos que 1999 resulta un año base que otorga mayor objetividad a las conclusiones, porque permite una mirada más extendida y menos sesgada por la peor crisis del país en su historia, dándonos un panorama asociado a un proceso y a cambios nacionales promedio (es decir, menos condicionado por la fuerte caída de casi $11 \%$ del PBI en 2002, lo cual sin duda fue un hecho inédito).

${ }^{18}$ Argentina no dispone de datos nacionales ni a nivel de la población rural. La información refiere a veintiocho aglomerados urbanos.

19 En realidad, la mirada por quintiles de población (e incluso por deciles) no nos permite ver la acumulación de ingresos que concentra la verdadera cúpula del poder económico en su total magnitud. Por ejemplo, el quintil 5 se compone del decil 9 y 10, cuya diferencia de ingresos es sustancial: mientras el decil 9 concentra el $15,6 \%$ de los ingresos nacionales el decil 10 triplica esta cifra (concentrando el $42,9 \%$ de los ingresos nacionales). Es más, al interior del decil 10 seguramente también se reproduce un subsector controlando la mayor parte de ese $43 \%$ de ingresos nacionales (Cuadro 2).

${ }^{20}$ Corresponde no olvidar la "década perdida" del ochenta, donde el crecimiento se estancó, alcanzando apenas el 1,2\% promedio anual para toda Latinoamérica. En aquella década hubo casos, como Argentina,

Geo UERJ - Ano 14, no. 23, v. 2, $2^{\circ}$ semestre de 2012 p. 717-745

ISSN: 1415-7543 E-ISSN: 1981-9021

http://www.e-publicacoes.uerj.br/index.php/geouerj 
Perú, Uruguay y Venezuela, sin crecimiento -o aún con tasas negativas para el promedio de los diez añossiendo las excepciones Chile, Colombia y Paraguay, cuya expansión fue de apenas 3\%, promedio anualpara toda la década. Tampoco podemos ignorar los limitados resultados de la década de los noventa (Cuadro 1). Es decir, dos décadas con crecimiento nulo o muy bajo en promedio que condicionaron y justificaron la caída de la participación en el PBI de los sectores de menores recursos.

${ }^{21}$ Debentomarse estas magnitudes con cierta precaución, porque la base del período que la CEPAL considera (2002) está muy influenciada por la crisis de Argentina (fue el año de máxima recesión: $11 \%$ de retroceso del PBI, Cuadro 1). Lo cual además influenció en países vecinos (como Uruguay, que también cayó un $11 \%)$. Y del mismo modo, Venezuela que tuvo en ese año su mayor recesión en décadas (-9\%). De hecho, el PBI de AL no creció en 2002 (0,4\%, Cuadro 1). Es decir, las mejoras que aparecen en el gráfico seguramente están algo sesgadas por un año base muy atípico en el devenir latinoamericano. La propia CEPAL (2011, p. 186) refiere a esto mismo, aunque bajo otras consideraciones, cuando identifica países que habrían tenido cambios mucho más significativos que el resto (entre ellos, Argentina y Venezuela) y que, por lo tanto, influyen más en los resultados promedio.

${ }^{22}$ Exactamente 28,7\%, mientras que en 1999 tenía el control del 37,8\%. O sea, hubo una caída de participación en los ingresos de casi $32 \%$ por parte del $10 \%$ más rico.

${ }^{23}$ Otros países donde el $10 \%$ más rico tiene un control importante de los ingresos son: Colombia (46,2 en 2010) y Chile (42,9\% en 2009).

${ }^{24}$ En efecto, en 2001 en Brasil el $20 \%$ más rico captaba casi el $68 \%$ de los ingresos y el $20 \%$ más pobre solo el 2\%.En 2009 mejoró esta distribución: el $20 \%$ más rico bajó su participación al $62 \%$ y el $20 \%$ más pobre subió moderadamente al 2,7\% (la caída de participación de los más ricos fue de 6 puntos porcentuales de los cuáles los más pobres sólo ganaron 0,7 puntos).

${ }^{25}$ El índice de Gini mide hasta qué punto la distribución del ingreso (o, en algunos casos, el gasto de consumo) entre individuosu hogares dentro de una economía se aleja de una distribución perfectamente equitativa (http://datos.bancomundial.org/indicador/SI.POV.GINI). Identifica la desigualdad de ingresos desde 0 (que refiere a la igualdad absoluta)a 1 (que indica inequidad absoluta).En general en el mapa mundial los países con menor desigualdad tienen índices menores a 0,25(Azerbaiyán, Dinamarca, Suecia, República Checa, Noruega, Eslovaquia). Valores superiores a 0,5 son considerados indicadores de fuerte desigualdad. Además, vale también tomar como referencia que 0,32 es el promedio de los países de la OCDE (como señala Ricardo Lagos; ver más arriba).

${ }^{26}$ En Argentina hay una diferencia en el número de aglomeraciones incluidas en un año y otro que hace que los datos disponibles no sean estrictamente comparables entre sí.

${ }^{27}$ Según datos de la conferencia de prensa de los máximos referentes de los tres organismos internacionales vinculados a esta problemática (Organización para la Agricultura y la Alimentación FAO-, Fondo Internacional de Desarrollo Agrícola -FIDA- y Programa Mundial de Alimentos -PMA-) celebrada el 14 de septiembre de 2010 en Roma.Argentina (al igual que otros latinoamericanos, como Costa Rica, Cuba, Chile, México, Uruguay) detenta una situación relativamente mejor, con una población subnutrida en los niveles más bajos del relevamiento de la FAO (menos del 5\% de la población total).Pero el problema existe y ética y humanamente no corresponde aceptar ninguna magnitud, por menor que sea. Enotros países latinoamericanos estos valores varían entre el $57 \%$ y el $10 \%$ de su respectiva población.

${ }^{28}$ Se estima que un $31,4 \%$ de la población es pobre y un 12,3\% es indigente (CEPAL, 2011: 66). Este cálculo está realizado en base a diecinueve países (Argentina, Bolivia, Brasil, Chile, Colombia, Costa Rica, Ecuador, Guatemala, El Salvador, Haití, Honduras, México, Nicaragua, Panamá, Paraguay, Perú, Venezuela,República Dominicana y Uruguay).

Artigo encaminhado para publicaçãoemnovembrode 2012.

Artigo aceito para publicaçãoemdezembro de 2012.

Geo UERJ - Ano 14, nº 23 , v. 2, $2^{\circ}$ semestre de 2012 p. $717-745$

ISSN: 1415-7543 E-ISSN: 1981-9021

http://www.e-publicacoes.uerj.br/index.php/geouerj 